\title{
Suitability of the RIPLS and IEPS for Discriminating Attitude Differences towards Interprofessional Education among Students of Healthcare Profession
}

\author{
Kingston Rajiah, ${ }^{1}$ Mari Kannan Maharajan, ${ }^{1}$ Suan Phaik Khoo, ${ }^{2}$ \\ Dinesh Kumar Chellappan, ${ }^{3}$ Ranjit De Alwis, ${ }^{4}$ Hui Cing Chui, ${ }^{1}$ Lui Lee Tan, \\ Yee Ning Tan, ${ }^{1}$ and Shin Yee Lau ${ }^{1}$ \\ ${ }^{1}$ Department of Pharmacy Practice, School of Pharmacy, International Medical University, 57000 Kuala Lumpur, Malaysia \\ ${ }^{2}$ Department of Oral Sciences, School of Dentistry, International Medical University, 57000 Kuala Lumpur, Malaysia \\ ${ }^{3}$ Department of Life Sciences, School of Pharmacy, International Medical University, 57000 Kuala Lumpur, Malaysia \\ ${ }^{4}$ Department of Community Medicine, School of Medicine, International Medical University, 57000 Kuala Lumpur, Malaysia
}

Correspondence should be addressed to Kingston Rajiah; kingrajiah@gmail.com

Received 28 April 2016; Revised 26 July 2016; Accepted 15 August 2016

Academic Editor: Eddie Denessen

Copyright (c) 2016 Kingston Rajiah et al. This is an open access article distributed under the Creative Commons Attribution License, which permits unrestricted use, distribution, and reproduction in any medium, provided the original work is properly cited.

Background. Interprofessional education provides students of healthcare programme an opportunity to collaborate with students from other disciplines and help them to get a training prior to entering the healthcare workforce. This study may help to select a suitable tool to discriminate attitude differences of healthcare professional students towards interprofessional education. Methods. A study, which was cross-sectional, was conducted at a private university in Malaysia to explore the two scales (RIPLS and IEPS) and their psychometric properties. Study participants comprised students from four different professions with at least one exposure or no previous exposure to IPE. Results. Both the scales (RIPLS and IEPS) have their own ability to detect differences in students' attitude towards IPE in their own way. However, the IEPS scale was able to detect differences within the gender, professions (both junior and senior students), and prior exposure to IPE. Conclusions. This study revealed that though both scales can be used to follow the impact of IPE in curricula, IEPS scale is more suitable than RIPLS to discriminate attitude differences among healthcare students. Educators may develop various strategies to observe students' behaviours and perceptions qualitatively and conduct longitudinal study to assess the outcomes of including IPE in curricula.

\section{Introduction}

Globally, many health systems are fragmented and struggling to manage unmet health needs, mainly due to the shortage of human resources. The World Health Organization (WHO) recognizes interprofessional collaboration in healthcare practice as an innovative strategy to strengthen the healthcare workforce and to deliver the highest quality of care [1]. To ensure meaningful and effective care for patients, healthcare professionals must be competent in their own profession and ready to work collaboratively as a team player in a healthcare team [2]. Asian healthcare settings are moving towards integrated healthcare delivery and encouraging professional collaboration across a range of care delivery. Considering the complexity in disease management protocols and rise in the elderly population, interprofessional collaborative practice is required to achieve effective healthcare management.

Interprofessional education (IPE) is an essential step forward in preparing a "collaborative practice-ready" healthcare professional students [3]. Interprofessional education during undergraduate programmes will enable the healthcare professional students to practice collaboratively, which will go on to optimize health services, strengthen healthcare systems, and improve health outcomes [4-6]. Interprofessional education occurs when there are two or more professionals learning with, from, and about each other [7]. There is active learning with and from other disciplines to improve collaboration between professionals and also to achieve a 
high quality of practice [8] in healthcare. Early exposure to IPE provides healthcare professional students an opportunity to collaborate with students from other discipline and serves as a platform for a future collaborative practice. Also, IPE serve as a link to connect students from various disciplines and may help them to strengthen their professional identity.

Recent reforms in health professional education in Asia are aimed to move health systems from fragmentation to a position of strength. Implementing IPE in healthcare professional education, especially at the undergraduate level, is a step forward to prepare the students to face the challenges in actual practice in the future. Previous reports suggested that there is a multitude of barriers to IPE implementation, including structural and organizational conflicts related to program length and size [5,9-11]. Gender, ethnicity, profession, and previous work experience in health and social care environments have significant role in predicting baseline professional identity [12-15]. Above all, variations in students' attitudes towards IPE (e.g., prejudices, stereotypes) may be the biggest barrier [16, 17]. Hence, understanding of the attitudes of healthcare professional students and the factors which influence their readiness may significantly help the educators and policy makers to evaluate the effectiveness of curricula which focus on IPE.

Given the reforms in healthcare professional education and development and implementation of new curricula focussing on IPE, reliable, validated tools for tracking the effectiveness of new curricula across various disciplines are needed. It will be an advantage if the evaluating tools are able to discriminate changes in the knowledge, skills, and attitudes of students in order to assess the effectiveness of the new curricula which are aimed at teaching interprofessional collaborative practice.

The RIPLS and IEPS are used among the medical and health professional students to measure their perceived attitudes and to determine their acceptance and readiness for interprofessional education during their studies. This study is aimed at finding out the tool which can distinguish students' attitudes towards IPE. We hypothesized that RIPLS and IEPS can discriminate attitude differences among specific groups (gender, profession, ethnicity, and prior IPE exposure).

\section{Material and Methods}

2.1. Participants and Setting. A cross-sectional study was conducted at a private university in Malaysia to explore the two scales (RIPLS and IEPS) and their psychometric properties. Study participants comprising students from the four professions with at least one or no previous exposure to IPE were recruited to complete the survey during the time period between June 2015 and November 2015. A total of 809 students from dentistry $(n=77)$, medicine $(n=232)$, health sciences $(n=277)$, and pharmacy $(n=223)$ participated in this study. Undergraduate students who were of varied ethnicity, age, and gender participated in the activity.

2.2. Collection of Data. This study used two standardised questionnaires. The RIPLS [18] consists of 19 items and the IEPS [19] consists of 12 items. Data on the students' gender, their course (profession), year of study (years 1 and 2 were considered as junior students while years 3,4 , and 5 as senior students), ethnicity, and previous exposure to IPE were gathered. The respondents had been asked to selfreport their previous IPE exposure (exposure to IPE in at least one occasion was considered as "Yes" and no exposure was considered as "No"). In this study, "self-reported IPE exposure" indicated that students had prior exposure to IPE.

2.3. Data Analysis. Descriptive analysis was used to provide an overview of the performance of each scale. Inferential statistics were used for further analysis. The mean scores of RIPLS and IEPS were compared among the specific groups. Positive attitude towards IPE and learning was represented by a higher mean for both RIPLS and IEPS. The "effect size" (using Cohen's $d$ ) test was used to examine the magnitude of the differences in the mean scores of the groups. Cohen's $d$ value of 0.2 was considered as a "small" effect size, 0.5 a "medium" effect size, and 0.8 a "large" effect size. Independent-sample $t$-test was used to analyse differences in the gender and one way analysis of variance (ANOVA) was used for other parameters (profession, year of study, ethnicity, and self-reported IPE exposure). Homogeneity of variance was tested by using Levene's test of equality of variances. Cronbach's $\alpha$ was used to assess the internal consistency of the scales.

\section{Results}

3.1. Participant Characteristics. Out of 975 students, a total of 809 responded, giving an $83 \%$ overall response rate. The response rate from different health profession students was $72 \%$ (232/320) from medicine, 89\% (223/251) from pharmacy, $71 \%$ (77/109) from dentistry, and 94\% (277/295) from health sciences. Students' demographic profile for all four professions, gender, year of study, ethnicity, and prior exposure to IPE, are represented in Table 1.

3.2. Differences by Gender. Levene's test showed nonsignificant results $(p=0.702)$ for the dependent variable indicating that the error variance of each dependent variable is equal across groups. The gender differences in attitudes between senior students for IEPS and RIPLS scales were compared. There was a significant gender difference detected by the IEPS scale between senior students $(t=2.502$, df $=433$, and $p=$ 0.04 ) (Cohen's $d=0.57)$. The mean scores of female senior students $(\mathrm{m}=83.4, \mathrm{SD}=7.48)$ were higher than those of their male counterparts $(\mathrm{m}=81.9, \mathrm{SD}=7.67)$. There was however no such difference with the RIPLS.

There was also no gender difference among the junior students regarding the IEPS and RIPLS (Table 2).

3.3. Differences by Professions. Levene's test showed that all four professions have met the assumption of homogeneity of variance. Results revealed that, among the senior and junior students, IEPS detected significant differences in attitudes 
TABLE 1: Participants and setting.

\begin{tabular}{|c|c|c|c|c|c|}
\hline & \multicolumn{4}{|c|}{ Profession } & \multirow[b]{2}{*}{$\begin{array}{c}\text { Total } \\
n=809\end{array}$} \\
\hline & $\begin{array}{c}\text { Dentistry } \\
n=77\end{array}$ & $\begin{array}{l}\text { Medicine } \\
n=232\end{array}$ & $\begin{array}{c}\text { Pharmacy } \\
n=223\end{array}$ & $\begin{array}{l}\text { Health sciences } \\
\quad n=277\end{array}$ & \\
\hline \multicolumn{6}{|l|}{ Gender } \\
\hline Male & $33(42.8 \%)$ & $80(34.4 \%)$ & $81(36.3 \%)$ & $68(24.5 \%)$ & $262(32.3 \%)$ \\
\hline Female & $44(57.1 \%)$ & $152(65.5 \%)$ & $142(63.7 \%)$ & $209(75.5 \%)$ & $547(67.7 \%)$ \\
\hline \multicolumn{6}{|c|}{ Year of study } \\
\hline Juniors & $27(35 \%)$ & 108 (46.5\%) & $100(44.8 \%)$ & $139(50.1 \%)$ & $374(46.2 \%)$ \\
\hline Seniors & $50(65 \%)$ & $124(53.5 \%)$ & $123(55.2 \%)$ & $138(49.9 \%)$ & $435(53.7 \%)$ \\
\hline \multicolumn{6}{|l|}{ Ethnicity } \\
\hline Malay & $3(3.8 \%)$ & $25(19.8 \%)$ & $68(30.4 \%)$ & $64(23.1 \%)$ & $160(19.7 \%)$ \\
\hline Chinese & $61(79.2 \%)$ & $126(54.3 \%)$ & $128(57.3 \%)$ & $131(47.2 \%)$ & $446(55.1 \%)$ \\
\hline Indian & $12(15.5 \%)$ & $69(29.7 \%)$ & $24(10.7 \%)$ & $78(28.1 \%)$ & $183(22.6 \%)$ \\
\hline Others & $1(1.2 \%)$ & $12(5.1 \%)$ & $3(1.3 \%)$ & $4(1.4 \%)$ & $20(2.4 \%)$ \\
\hline \multicolumn{6}{|c|}{ Prior exposure to IPE } \\
\hline Yes & $23(29.9 \%)$ & $108(46.5 \%)$ & $123(55.2 \%)$ & $77(27.7 \%)$ & $331(40.9 \%)$ \\
\hline No & $54(70.1 \%)$ & $124(53.5 \%)$ & $100(44.8 \%)$ & $200(72.3 \%)$ & $478(59.1 \%)$ \\
\hline
\end{tabular}

TABLE 2: Mean scores and significant differences of the RIPLS and IEPS by student gender.

\begin{tabular}{|c|c|c|c|c|c|}
\hline & $N$ & Mean & SD & $t$ & Cohen's $d$ \\
\hline \multicolumn{6}{|l|}{ Juniors } \\
\hline \multicolumn{6}{|l|}{ RIPLS } \\
\hline Male & 124 & 77.6 & 6.32 & \multirow{2}{*}{$\begin{array}{l}t=1.20, \mathrm{df}= \\
372, p=0.52\end{array}$} & \multirow{2}{*}{ NA } \\
\hline Female & 250 & 76.4 & 6.58 & & \\
\hline \multicolumn{6}{|l|}{ IEPS } \\
\hline Male & 124 & 85.6 & 7.52 & $t=2.11, \mathrm{df}=$ & \multirow{2}{*}{ NA } \\
\hline Female & 250 & 83.5 & 7.37 & $372, p=0.54$ & \\
\hline
\end{tabular}

Seniors

RIPLS

\begin{tabular}{|c|c|c|c|c|c|}
\hline Male & 138 & 74.8 & 6.28 & \multirow{2}{*}{$\begin{array}{l}t=1.40, \mathrm{df}= \\
433, p=0.62\end{array}$} & \multirow[t]{2}{*}{ NA } \\
\hline Female & 297 & 73.4 & 6.34 & & \\
\hline \multicolumn{6}{|l|}{ EPS } \\
\hline Male & 138 & 81.9 & 7.67 & \multirow{2}{*}{$\begin{array}{l}t=2.502, \mathrm{df}= \\
433, p=0.04^{*}\end{array}$} & \multirow{2}{*}{0.28} \\
\hline Female & 297 & 83.4 & 7.48 & & \\
\hline
\end{tabular}

${ }^{*}$ Statistically significant at 0.05 level. RIPLS: readiness for interprofessional learning scale; IEPS: interdisciplinary education perception scale; df: degrees of freedom; NA: not applicable.

across the different professions $((F(3,370)=17.280, p=$ $0.015)$ and $(F(3,431)=17.479, p=0.012)$, respectively). Among the junior students, IEPS detected a significant difference between pharmacy and medical students (Cohen's $d=0.54$ ). Among the senior students, IEPS detected a significant difference between pharmacy and dental students (Cohen's $d=0.57$ ). The RIPLS did not detect any significant difference across the four professions among both the junior and the senior students (Table 3).

3.4. Differences by Ethnicity. Both the RIPLS and IEPS scales did not show any significant differences in attitudes relating to ethnicity among junior and senior students (Table 4).
3.5. Differences by Self-Reported IPE Exposure. Though RIPLS did not detect any differences in attitudes in relation to prior exposure to IPE, the differences were detected by the IEPS $(t=1.904, \mathrm{df}=807$, and $p=0.04)$. Students who had no prior exposure $(\mathrm{m}=83.8, \mathrm{SD}=7.21)$ scored significantly lower than those reporting at least one exposure to IPE $(\mathrm{m}=85.7$, $\mathrm{SD}=6.89$ ), Cohen's $d=0.86$ (Table 5).

\section{Discussion}

With a high response rate of over $70 \%$ from different disciplines, these results are strengthened by the responses from large numbers of participants. To further analyse the results, the data were aggregated across the profession as subgroups.

The two commonly used RIPLS and the IEPS attitude scales were taken to compare their psychometric properties in discriminating their differences on IPL among healthcare professional students. The results from this study showed that both RIPLS and IEPS were able to discriminate the attitudes of students of various healthcare professions. These findings support those of the earlier reports, which measured the attitudes of students towards interprofessional learning $[18,19]$.

Neither the IEPS nor the RIPLS scales detected gender differences among junior students. However, the IEPS scale indicated that there was a decline in the attitude towards interprofessional learning among the male senior students. These findings concurred with an earlier report in 2013 by Lie et al. [18]. Based on IEPS, female students have more positive IPE attitudes compared to males in the later stages of their courses. The differences in attitudes between genders would be mediated by the level of training. A more positive attitude towards IPE through training may reflect the openness of the students' attitude towards learning and collaboration with other professions.

Attitude of students towards IPE becomes more negative as they progress through their course [18]. The RIPLS did not detect any significant difference in attitude between junior 
TABLE 3: Mean scores and significant differences of the RIPLS and IEPS by student profession.

\begin{tabular}{|c|c|c|c|c|c|}
\hline & $N$ & Mean & SD & $F$ & Cohen's $d$ \\
\hline \multicolumn{6}{|l|}{ Juniors } \\
\hline \multicolumn{6}{|l|}{ RIPLS } \\
\hline Dentistry & 27 & 72.3 & 6.32 & \multirow{4}{*}{$\begin{array}{c}F(3,370)= \\
11.458 \\
p=0.13\end{array}$} & \multirow{4}{*}{ NA } \\
\hline Medicine & 108 & 75.7 & 6.58 & & \\
\hline Pharmacy & 100 & 77.8 & 6.52 & & \\
\hline $\begin{array}{l}\text { Health } \\
\text { sciences }\end{array}$ & 139 & 73.4 & 6.37 & & \\
\hline \multicolumn{6}{|l|}{ IEPS } \\
\hline Dentistry & 27 & 81.4 & 7.33 & \multirow{4}{*}{$\begin{array}{c}F(3,370)= \\
17.280, \\
p=0.015^{*}\end{array}$} & $\begin{array}{l}\text { Pharm versus } \\
\text { dental }=0.47\end{array}$ \\
\hline Medicine & 108 & 79.8 & 7.59 & & $\begin{array}{c}\text { Pharm versus } \\
\text { med }=0.54\end{array}$ \\
\hline Pharmacy & 100 & 84.3 & 7.53 & & - \\
\hline $\begin{array}{l}\text { Health } \\
\text { sciences }\end{array}$ & 139 & 82.4 & 7.38 & & $\begin{array}{c}\text { Pharm versus } \\
\text { health sci = } \\
0.45\end{array}$ \\
\hline \multicolumn{6}{|l|}{ Seniors } \\
\hline \multicolumn{6}{|l|}{ RIPLS } \\
\hline Dentistry & 50 & 72.7 & 6.37 & \multirow{4}{*}{$\begin{array}{c}F(3,431)= \\
12.054 \\
p=0.14\end{array}$} & \multirow{4}{*}{ NA } \\
\hline Medicine & 124 & 75.8 & 6.45 & & \\
\hline Pharmacy & 123 & 77.4 & 6.74 & & \\
\hline $\begin{array}{l}\text { Health } \\
\text { sciences }\end{array}$ & 138 & 73.1 & 6.39 & & \\
\hline \multicolumn{6}{|l|}{ IEPS } \\
\hline Dentistry & 50 & 82.8 & 7.13 & \multirow{4}{*}{$\begin{array}{c}F(3,431)= \\
17.479, \\
p=0.012^{*}\end{array}$} & $\begin{array}{c}\text { Pharm versus } \\
\text { dental }=0.57\end{array}$ \\
\hline Medicine & 124 & 84.3 & 7.85 & & $\begin{array}{c}\text { Pharm versus } \\
\text { med }=0.49\end{array}$ \\
\hline Pharmacy & 123 & 85.4 & 7.52 & & - \\
\hline $\begin{array}{l}\text { Health } \\
\text { sciences }\end{array}$ & 138 & 83.7 & 7.76 & & $\begin{array}{c}\text { Pharm versus } \\
\text { health sci = } \\
0.48\end{array}$ \\
\hline
\end{tabular}

* Statistically significant at 0.05 level. RIPLS: readiness for interprofessional learning scale; IEPS: interdisciplinary education perception scale; $F$ : test of the equality of two variances; NA: not applicable.

and senior students across the different professions. This was, however, picked up by the IEPS. The attitude of medical students towards IPE was poor at the junior level, whereas this occurred at the senior level of dental students. At junior level, medical students may have a strong professional identity and the tendency to view doctors as having a predominance over the other healthcare professionals [20]. Medical students may also be less likely to consider "shared learning with other health care students" [11]. Medical students may consider themselves as more patient-caring persons than any other professions [21]. The negative attitude of medical students towards IPE may be due to their limited patient exposure in the junior level $[9,22]$. At the senior level, the medical students begin to be exposed to the clinical settings. This may somewhat change their attitudes towards interprofessional leaning $[23,24]$. Dental students who were at senior level
TABLE 4: Mean scores and significant differences of the RIPLS and IEPS by student ethnicity.

\begin{tabular}{lccccc}
\hline & $N$ & Mean & SD & $F$ & Cohen's \\
\hline Juniors & & & & & \\
RIPLS & & & & & \\
Malay & 86 & 71.4 & 6.45 & & \\
Chinese & 238 & 74.5 & 6.68 & $F(3,370)=10.587$, & NA \\
Indian & 80 & 75.2 & 6.47 & $p=0.12$ & \\
Others & 12 & 70.3 & 6.42 & & NA \\
IEPS & & & & & \\
Malay & 86 & 79.2 & 7.56 & & \\
Chinese & 238 & 79.5 & 7.45 & $F(3,370)=15.807$, & \\
Indian & 80 & 80.6 & 7.36 & $p=0.15$ & \\
Others & 12 & 79.7 & 7.21 & & NA \\
\hline Seniors & & & & & \\
RIPLS & & & & & \\
Malay & 74 & 71.8 & 6.36 & & \\
Chinese & 215 & 74.9 & 6.49 & $F(3,431)=9.872$, & \\
Indian & 103 & 76.1 & 6.60 & $p=0.11$ & \\
Others & 8 & 73.7 & 6.25 & & \\
IEPS & & & & & \\
Malay & 74 & 80.8 & 7.81 & & \\
Chinese & 215 & 81.2 & 7.74 & $F(3,431)=14.075$, & \\
Indian & 103 & 83.3 & 7.68 & $p=0.14$ & \\
Others & 8 & 80.4 & 7.32 & & \\
\hline
\end{tabular}

TABLE 5: Mean scores for RIPLS and IEPS by prior exposure.

\begin{tabular}{cccccc}
\hline $\begin{array}{l}\text { Prior } \\
\text { exposure } \\
\text { to IPE }\end{array}$ & $N$ & Mean & SD & $t$ & Cohen's $d$ \\
\hline $\begin{array}{l}\text { RIPLS } \\
\text { Yes }\end{array}$ & 331 & 76.8 & 6.57 & $t=3.402, \mathrm{df}=807$, & $\mathrm{NA}$ \\
No & 478 & 73.4 & 7.85 & $p=0.07$ & \\
\hline $\begin{array}{l}\text { IEPS } \\
\text { Yes }\end{array}$ & 331 & 85.7 & 6.89 & $t=1.904, \mathrm{df}=807$, & 0.86 \\
No & 478 & 83.8 & 7.21 & $p=0.04^{*}$ & \\
\hline
\end{tabular}

${ }^{*}$ Statistically significant at 0.05 level. RIPLS: readiness for interprofessional learning scale; IEPS: interdisciplinary education perception scale; df: degrees of freedom; NA: not applicable.

have limited exposure to other professionals as they progress on, unlike the earlier years where they study together with medical students. Studies have shown that organisational factors such as curriculum overload, propagated negative attitudes towards dental students from other professions, and professional stereotyping could have an effect on the dental students' attitude towards IPE [25]. In addition, it is also possible that once the dental students are exposed to clinical setting, they begin to perceive strong professional identity [26]. They may feel that the other professions do not have a significant role in clinical decision-making in dentistry and think that the clinical problem-solving skills can only 
be learnt effectively with students from their own discipline [27]. However, it is encouraging to know that junior dental students did not have negative attitudes towards IPE. Blue (2013) reported that dental students' attitudes changed over the course of the study period as they moved to higher semesters [28]. She also stated that, along with enhanced professional responsibility, professional identity also increased among dental students. Educators and policy makers should develop various strategies to incorporate interprofessional working sessions in the dental clinical setting to help bring positive outcomes among students.

The results showed that the ethnicity of health care professional students does not affect their attitude towards IPE. This clearly indicated that although the students were from different ethnic background, it does not influence their attitude towards IPE. Although cross-sectional studies have suggested that ethnic diversity [29] may have a negative impact on social cohesion, there is no such impact on their attitude towards IPE [30, 31].

The IEPS was able to differentiate the attitudes between the healthcare professional students who had a prior exposure to IPE. This result was different from those of an earlier report, in which RIPLS has detected such changes in students' attitude [15]. The exact reason for this change may not be determined in the present study. However, it is clear that IEPS is better able to discriminate the attitudes of all healthcare professional students compared to RIPLS.

In summary, both the scales (RIPLS and IEPS) have their own ability to detect differences in the students' attitude towards IPE. The IEPS was able to detect gender differences among senior healthcare profession students. The IEPS was able to detect differences among various professions in both the junior and senior students. Also, the IEPS was able to discriminate the attitudes of all healthcare professional students who had a prior exposure to IPE.

Based on the findings from this study, IEPS establishes superiority over RIPLS in finding the attitude differences among students from different healthcare professions.

\section{Limitation}

Generalising globally may be limited as the study was undertaken in a single Malaysian university. It is also unclear if either scale is useful in following attitude change longitudinally during the course of the different programmes. In this study we have only examined the subgroup differences (gender, profession, ethnicity, and prior exposure).

\section{Conclusions}

This study revealed that although both scales can be used to follow the impact of IPE in the curricula, the IEPS is more suitable compared to the RIPLS in discriminating attitude differences among healthcare students. Educators and policy makers should develop various strategies to observe students' behaviours and perceptions qualitatively. In addition, longitudinal studies to assess the outcome of IPE in the curricula will be useful in order to strengthen the healthcare workforce and to deliver the highest quality of care for the patients.

\section{Competing Interests}

The authors declare that they have no competing interests.

\section{References}

[1] World Health Organization, Framework for Action on Interprofessional Education and Collaborative Practice, World Health Organization, Geneva, Switzerland, 2010, http://apps .who.int/iris/bitstream/10665/70185/1/WHO_HRH_HPN_10.3 _eng.pdf.

[2] U. Hylin, K. Lonka, and S. Ponzer, "Students' approaches to learning in clinical interprofessional context," Medical Teacher, vol. 33, no. 4, pp. e204-e210, 2011.

[3] J. L. Jacobs, D. D. Samarasekera, W. K. Chui et al., "Building a successful platform for interprofessional education for health professions in an Asian university," Medical Teacher, vol. 35, no. 5, pp. 343-347, 2013.

[4] S. Morison, "Effective interprofessional education: argument, assumption and evidence," in Learning in Health and Social Care, H. Barr, I. Koppel, S. Reeves, M. Hammick, and D. Freeth, Eds., vol. 5, no. 3, p. 166, Wiley, Hoboken, NJ, USA, 2006.

[5] M. Hammick, D. Freeth, I. Koppel, S. Reeves, and H. Barr, "A best evidence systematic review of interprofessional education: BEME Guide no. 9," Medical Teacher, vol. 29, no. 8, pp. 735-751, 2007.

[6] K. Mann, J. Sargeant, and T. Hill, "Knowledge translation in interprofessional education: what difference does interprofessional education make to practice?" Learning in Health and Social Care, vol. 8, no. 3, pp. 154-164, 2009.

[7] Centre for Advancement of Interprofessional Education (CAIPE), Defining IPE, http://www.caipe.org.uk/resources/.

[8] D. Greenfield, P. Nugus, J. Travaglia, and J. Braithwaite, "Auditing an organization's interprofessional learning and interprofessional practice: the interprofessional praxis audit framework (IPAF)," Journal of Interprofessional Care, vol. 24, no. 4, pp. 436449, 2010.

[9] L. Honan, D. B. Fahs, J. S. Talwalkar, and G. Kayingo, "Interprofessional learning: perceptions of first year health students," Journal of Nursing Education and Practice, vol. 5, no. 6, pp. 3949, 2015.

[10] P. J. Furness, H. R. Armitage, and R. Pitt, "Qualitative evaluation of interprofessional learning initiatives in practice: application of the contact hypothesis," International Journal of Medical Education, vol. 3, pp. 83-91, 2012.

[11] M. Horsburgh, R. Lamdin, and E. Williamson, "Multiprofessional learning: the attitudes of medical, nursing and pharmacy students to shared learning," Medical Education, vol. 35, no. 9, pp. 876-883, 2001.

[12] S. Coster, I. Norman, T. Murrells et al., "Interprofessional attitudes amongst undergraduate students in the health professions: a longitudinal questionnaire survey," International Journal of Nursing Studies, vol. 45, no. 11, pp. 1667-1681, 2008.

[13] M. Wilhelmsson, S. Ponzer, L.-O. Dahlgren, T. Timpka, and T. Faresjö, "Are female students in general and nursing students more ready for teamwork and interprofessional collaboration in healthcare?" BMC Medical Education, vol. 11, article 15, 2011. 
[14] K. C. Pollard, M. E. Miere, M. Gilchrist, and A. Sayers, "A comparison of interprofessional perceptions and working relationships among health and social care students: the results of a 3 -year intervention," Health and Social Care in the Community, vol. 14, no. 6, pp. 541-552, 2006.

[15] V. R. Curran, D. Sharpe, K. Flynn, and P. Button, "A longitudinal study of the effect of an interprofessional education curriculum on student satisfaction and attitudes towards interprofessional teamwork and education," Journal of Interprofessional Care, vol. 24, no. 1, pp. 41-52, 2010.

[16] A. G. Greer, M. Clay, A. Blue, C. H. Evans, and D. Garr, "The status of interprofessional education and interprofessional prevention education in academic health centers: a national baseline study," Academic Medicine, vol. 89, no. 5, pp. 799-805, 2014.

[17] K. A. Puntillo and J. L. McAdam, "Communication between physicians and nurses as a target for improving end-of-life care in the intensive care unit: challenges and opportunities for moving forward," Critical Care Medicine, vol. 34, no. 11, pp. S332-S340, 2006.

[18] D. A. Lie, C. C. Fung, J. Trial, and K. Lohenry, "A comparison of two scales for assessing health professional students' attitude toward interprofessional learning," Medical Education Online, vol. 18, article 21885, 2013.

[19] G. Parsell and J. Bligh, "The development of a questionnaire to assess the readiness of health care students for interprofessional learning (RIPLS)," Medical Education, vol. 33, no. 2, pp. 95-100, 1999.

[20] H. Dargahi, M. Shirazi, and S. A. Yazdanparast, "Interprofessional learning: the attitudes of medical, nursing and pharmacy students to shared learning at Tehran University of Medical Sciences," Thrita Journal of Medical Sciences, vol. 1, no. 2, pp. 44-48, 2012.

[21] G. Hawkes, I. Nunney, and S. Lindqvist, "Caring for attitudes as a means of caring for patients-improving medical, pharmacy and nursing students' attitudes to each other's professions by engaging them in interprofessional learning," Medical Teacher, vol. 35, no. 7, pp. e1302-e1308, 2013.

[22] J. N. Hudson, A. Lethbridge, S. Vella, and P. Caputi, "Decline in medical students' attitudes to interprofessional learning and patient-centredness," Medical Education, vol. 50, no. 5, pp. 550559, 2016.

[23] Z. Aziz, L. C. Teck, and P. Y. Yen, "The attitudes of medical, nursing and pharmacy students to inter-professional learning," Procedia-Social and Behavioral Sciences, vol. 29, pp. 639-645, 2011.

[24] R. Cant, M. Leech, and K. Hood, "Factors affecting Australian medical students' attitudes to interprofessional education; validity of the Readiness for Inter-professional Learning Scale-Med," Journal of Interprofessional Education \& Practice, vol. 1, no. 3-4, pp. 90-96, 2015.

[25] R. Ajjawi, S. Hyde, C. Roberts, and G. Nisbet, "Marginalisation of dental students in a shared medical and dental education programme," Medical Education, vol. 43, no. 3, pp. 238-245, 2009.

[26] S. Morison, J. Marley, and S. Machniewski, "Educating the dental team: exploring perceptions of roles and identities," British Dental Journal, vol. 211, no. 10, pp. 477-483, 2011.

[27] F. B. Colonio Salazar, M. Andiappan, D. R. Radford, and J. E. Gallagher, "Attitudes of the first cohort of student groups trained together at the University of Portsmouth Dental Academy towards dental interprofessional education," European Journal of Dental Education, 2016.

[28] C. M. Blue, "Cultivating professional responsibility in a dental hygiene curriculum," Journal of Dental Education, vol. 77, no. 8, pp. 1042-1051, 2013.

[29] K. Rajiah and C. Ving, "An assessment of pharmacy students' knowledge, attitude, and practice toward oral health: an exploratory study," Journal of International Society of Preventive and Community Dentistry, vol. 4, no. 4, pp. s56-s62, 2014.

[30] R. D. Putnam, "E pluribus unum: diversity and community in the twenty-first century the 2006 johan skytte prize lecture," Scandinavian Political Studies, vol. 30, no. 2, pp. 137-174, 2007.

[31] L. Morales, "Assessing the effects of immigration and diversity in europe: introduction to the special issue," Journal of Elections, Public Opinion and Parties, vol. 23, no. 3, pp. 241-254, 2013. 


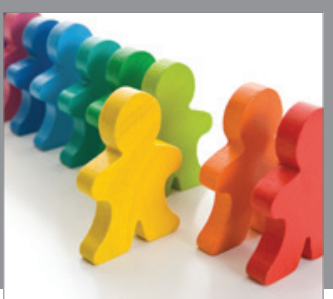

Autism

Research and Treatment
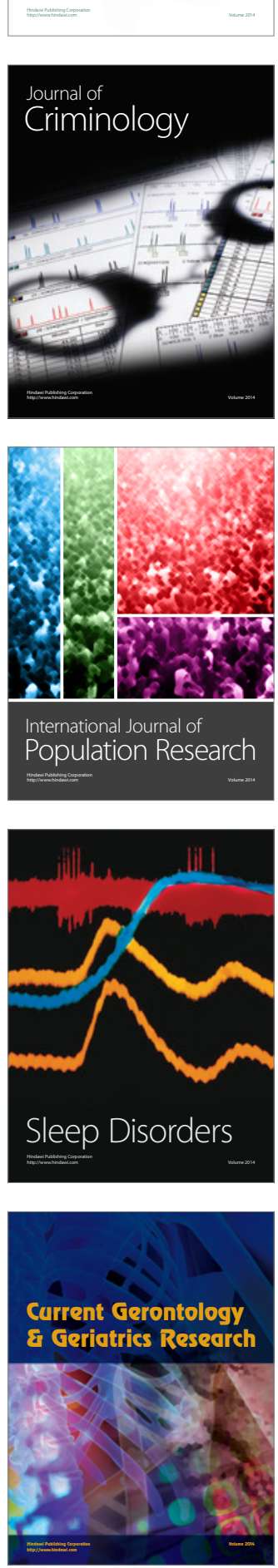

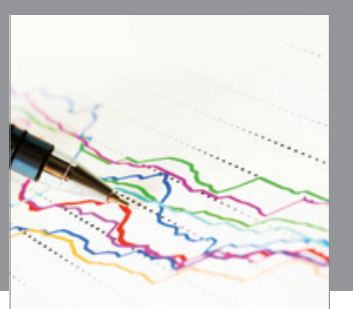

Economics

Research International
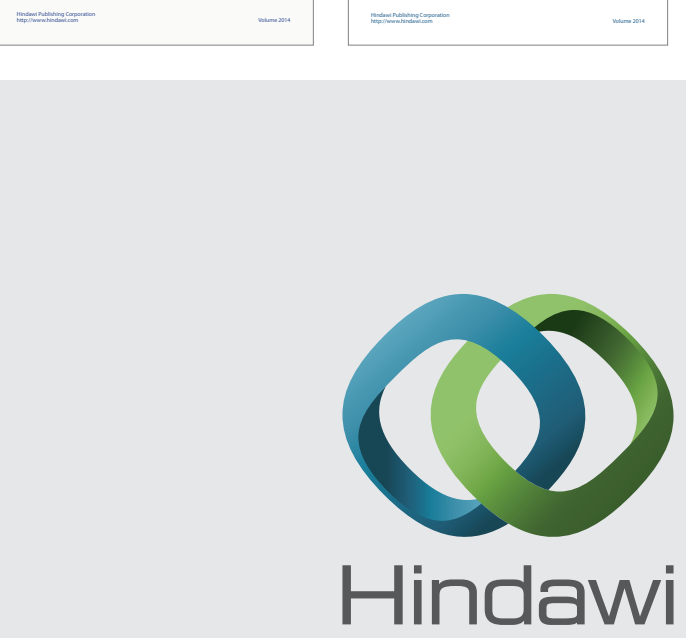

Submit your manuscripts at

http://www.hindawi.com
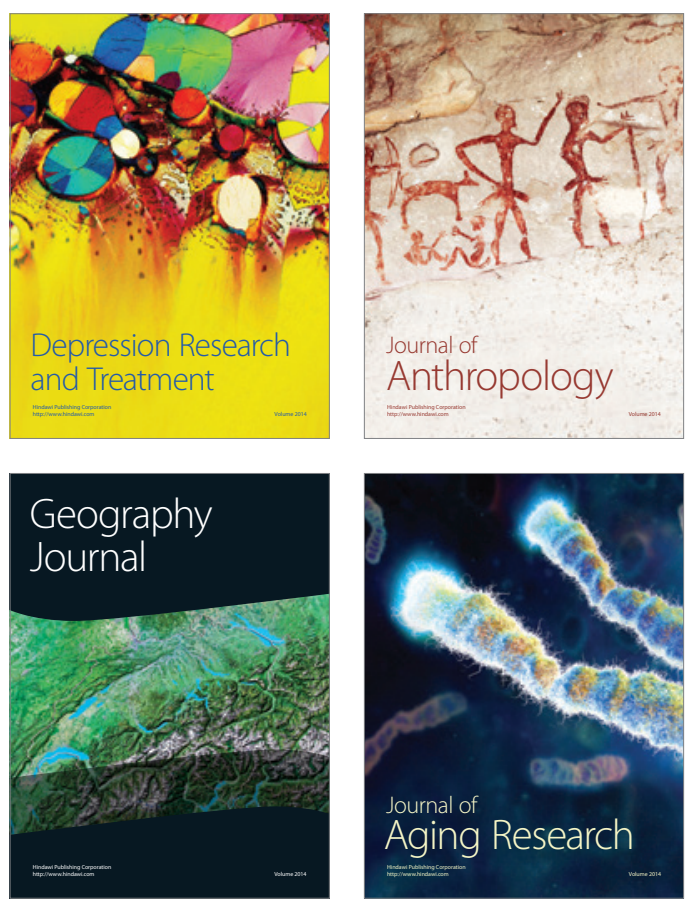
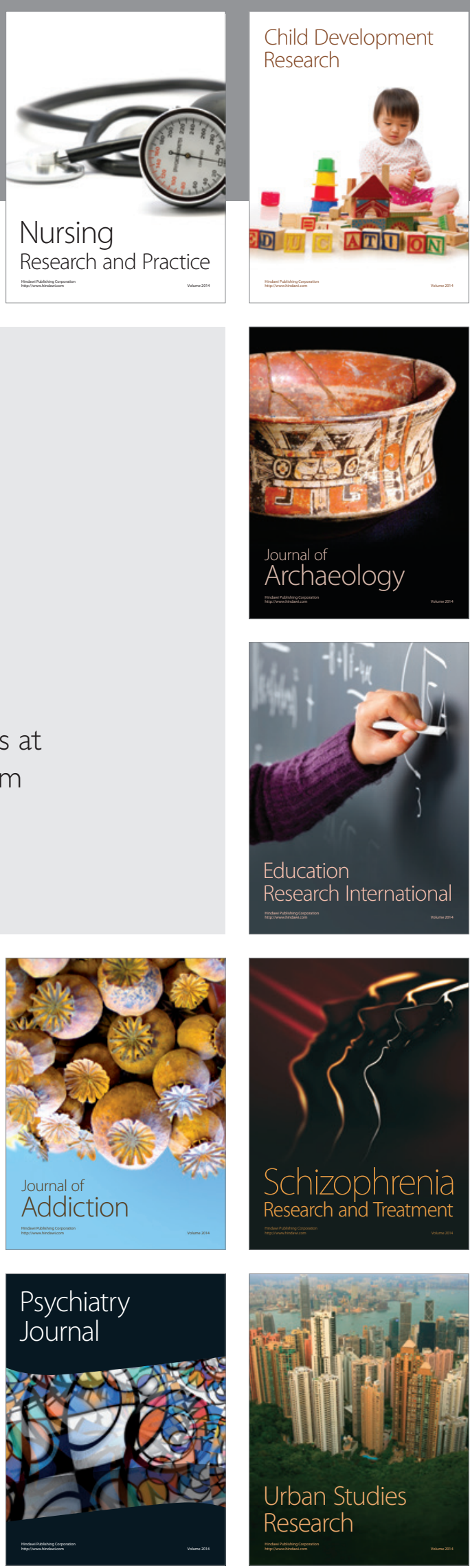